\title{
Percutaneous ultrasound-guided drainage of the biliary tree in palliative treatment of mechanical jaundice: 17 years of experience
}

\author{
Marcin Bednarek, Piotr Budzyński, Marek Poźniczek, Kazimierz Rembiasz \\ $2^{\text {nd }}$ Chair of Surgery, Jagiellonian University Medical College, Krakow, Poland
}

Videosurgery Miniinv 2012; 7 (3): 193-196 DOI: 10.5114/wiitm.2011.28896

\begin{abstract}
Introduction: Advanced malignant tumours involving the head of the pancreas, gallbladder or extrahepatic bile ducts usually lead to the development of cholestasis. In such cases improvement of the quality of life of patients can be achieved with the decompression of jaundice. Endoscopic implantation of self-expanding or (seldom) rigid plastic stents into the biliary tree constitutes the most common technique allowing for restoration of bile duct patency. In some patients however the use of such a procedure is technically impossible. In this particular group percutaneous drainage of the biliary tree can constitute the only method of management.

Aim: Presentation of our experience with the use of percutaneous ultrasound-guided drainage of the biliary tree in patients with mechanical jaundice resulting from malignant tumours.

Material and methods: There were 852 patients with mechanical jaundice resulting from malignant neoplasms treated in the $2^{\text {nd }}$ Chair of Surgery of Jagiellonian University Medical College from January 1994 to December 2010. In 199 of them jaundice was decompressed by means of open - radical or palliative - surgical operations. In 539 patients endoscopic treatment was implemented while in 114 of them percutaneous ultrasound-guided drainage was performed.

Results: In 5 patients percutaneous drainage was introduced to prepare them for radical surgical treatment, while in the remaining 109 it constituted the definitive way of management. The average hospitalization time for women was 6.5 days (range: $1-22$ days) and proved to be twice as short as in men - 12.2 days (range: 1-38 days). The duration of percutaneous drainage prior to surgical treatment averaged 7.2 days (range: 6-10 days). Mean volume of the bile drained during the first day was $370 \mathrm{ml}$ (range: $10-1300 \mathrm{ml}$ ), increased to $450 \mathrm{ml}$ (range: 100-1150 ml) during the second day and reached $780 \mathrm{ml}$ (range: $80-1600 \mathrm{ml}$ ) during the third day. Mean bilirubin level before the drainage was 320-23 $\mu \mathrm{mol} / \mathrm{l}$ (range: 658-130.7 $\mu \mathrm{mol} / \mathrm{l}$ ) and decreased by half before discharge or before the operation, reaching on average $181.87 \mu \mathrm{mol} / \mathrm{l}$ (range: $14.5-343 \mu \mathrm{mol} / \mathrm{l})$.

Conclusions: Complications of the percutaneous ultrasound-guided technique were found sporadically and resulted from leakage of the bile into the peritoneum.
\end{abstract}

Key words: percutaneous drainage, biliary tree, mechanical jaundice. 


\section{Introduction}

Advanced malignant tumours involving mainly the head of the pancreas, gallbladder or extrahepatic bile ducts usually lead to the development of cholestasis. In patients with an advanced neoplastic process, improvement of the quality of life of patients can be achieved with the decompression of jaundice. Endoscopic implantation of self-expanding or less frequently rigid plastic stents into the biliary tree constitutes the most common technique allowing for restoration of bile duct patency. In some patients such decompression of mechanical jaundice may be impossible due to for example an advanced neoplastic process, which prevents stent implantation or radical stomach resection. In this particular group percutaneous drainage of the biliary tree can constitute the only method of management.

\section{Aim}

The aim of the study was to present our experience with the use of percutaneous ultrasound-guided drainage of the biliary tree during a period of 17 years in patients with mechanical jaundice resulting from malignant tumours.

\section{Material and methods}

From January 1994 to December 2010, 852 patients with mechanical jaundice resulting from malignant neoplasms were treated in the $2^{\text {nd }}$ Chair of Surgery of Jagiellonian University Medical College. In 199 of them jaundice was decompressed by means of open - radical or palliative - surgical operations. Five hundred and thirty-nine patients were managed endoscopically while in the remaining 114 percutaneous ultrasound-guided drainage was performed. The latter group was analysed. It consisted of 67 women (58.8\%) and 47 men (41.1\%). Female median age was 67.1 years old (range: $46-89$ years old) and male 63 years old (range: $51-90$ years old). In $87 \%$ of patients mechanical jaundice resulted from pancreatic, gallbladder or bile duct (99 patients) carcinoma, and in the remaining 15 (13\%) from neoplasms of the stomach, large bowel or kidney. Percutaneous drainage was performed in 109 patients disqualified from radical surgery due to the advanced stage of a disease or lack of consent to the procedure. In 5 it was employed to prepare them for elective surgical treatment. The patients were qualified for percutaneous drainage based on classic ultrasound.
Endoscopic retrograde cholangiopancreatography (ERCP), which excluded such means of bile duct decompression, was previously performed in each of them.

\section{Technique of the procedure}

At first the ultrasound equipment used for percutaneous drainage was a Combison 320, Kretz equipped with a 4-5 MHz sector probe, then a HITACHI EUB 6000 with a $3.5 \mathrm{MHz}$ sector probe, and currently a LOGIQ 7 3.5-5 MHz sector probe. After having chosen a suitable injection site and direction of a needle, an incision of about 2-3 mm was made in the abdominal wall under local anaesthesia. Keeping the needle on course, a pigtail drainage catheter was placed into the bile ducts (in the study, we used $9 \mathrm{~F}$ Balton drainage catheters and the "drain-overneedle" technique). Ultrasound was employed to guide its route. The drain was inserted into the lumen of the bile ducts and the guide wire was removed. Having achieved bile outflow, it was stabilized with cutaneous suture and left in the "flowing" position.

\section{Results}

The average hospitalization time for women was 6.5 days (range: $1-22$ days) and proved to be twice as short as in men - 12.2 days (range: 1-38 days). The duration of percutaneous drainage prior to surgical treatment averaged 7.2 days (range: 6-10 days). Mean volume of the bile drained during the first day was $370 \mathrm{ml}$ (range: $10-1300 \mathrm{ml}$ ), increased to $450 \mathrm{ml}$ (range: 100-1150 $\mathrm{ml}$ ) during the second day and reached $780 \mathrm{ml}$ (range: $80-1600 \mathrm{ml}$ ) during the third day. Mean bilirubin level before the drainage was 320$23 \mu \mathrm{mol} / /$ (range: 658-130.7 $\mu \mathrm{mol} / \mathrm{l}$ ) and it decreased by half before discharge or before the operation reaching on average $181.87 \mu \mathrm{mol} / \mathrm{l}$ (range: 14.5-343 $\mu \mathrm{mol} / \mathrm{l})$. The patients reported an improved state of being, especially remission of pruritus. Proper faeces, and a bit later urine colour, occurred together with bilirubin level decrease in the blood. Out of 114 patients qualified for ultrasound-guided percutaneous drainage, 3 cases were unsuccessful despite numerous attempts. Spontaneous fall out of the drain (2 patients) or its accidental removal (1 patient) were the reasons for the second procedure on the $2^{\text {nd }}-3^{\text {rd }}$ day following the original drainage. Drain obstruction, which occurred on the $3^{\text {rd }}$ post-drainage day, was 
Table I. Localization of the tumour

\begin{tabular}{|c|c|c|c|c|}
\hline Tumour & & Women & Men & Together \\
\hline \multirow[t]{2}{*}{ Pancreas } & Head & 18 & 18 & 36 \\
\hline & Body & 2 & 1 & 3 \\
\hline Papilla of Vater & & 4 & 3 & 7 \\
\hline \multirow[t]{3}{*}{ Biliary tree } & Extrahepatic & 2 & 4 & 6 \\
\hline & Klatzkin tumour & 1 & 2 & 3 \\
\hline & Hilum of the liver & 10 & 8 & 18 \\
\hline Gallbladder & & 23 & 3 & 26 \\
\hline \multirow[t]{5}{*}{ Other } & Stomach & 2 & 5 & 7 \\
\hline & Right colonic flexure & 1 & 0 & 1 \\
\hline & Sigmoid colon & 2 & 2 & 4 \\
\hline & Rectum & 1 & 1 & 2 \\
\hline & Kidney & 1 & 0 & 1 \\
\hline Together & & 67 & 47 & 114 \\
\hline
\end{tabular}

observed in 1 patient. Endoscopic biliary stenting was performed. Bile leakage around the drain took place in 3 patients. It remitted spontaneously. The most serious complication, biliary peritonitis, occurred in 1 patient. Ten patients died after drainage during hospitalization (4 women and 6 men), due to an advanced neoplastic process (9 patients) or biliary peritonitis (1 patient).

\section{Discussion}

Mechanical jaundice, which is one of the early symptoms of neoplasms involving the head of the pancreas, bile ducts and gallbladder, may also occur as metastatic carcinoma of the alimentary tract (stomach, large bowel), urinary system, and reproductive or lymphatic system $[1,2]$.

Different methods are employed in management of mechanical jaundice resulting from malignant tumours: (1) endoscopic stenting of the main biliary tract with self-expanding or plastic stents, (2) ultrasound, or less frequently computed tomography guided percutaneous drainage, (3) "rendezvous" technique proposed by Sciume and Geraci [3-7], a combination of ERCP with percutaneous drainage, (4) surgical treatment - mainly bypass anastomoses [5, 7].
Endoscopic stenting is the method most commonly used to decompress mechanical jaundice [1, 2 , 7]. In patients who cannot undergo such a procedure and surgical treatment poses too much risk, percutaneous drainage might be a solution [3, 5, 7-9]. Mechanical jaundice decompression is substantial before elective surgical treatment and results in fewer complications in the post-operative period, including a lower morbidity rate [4, 5, 10-12]. Drainage lasts 2-3 weeks on average, and sometimes even about 4 weeks $[10,12]$. The preparation time before the surgery in our patients was a bit shorter, and amounted to 7-10 days. Some authors emphasize the crucial role of bile duct percutaneous drainage combined with ERCP, called the "rendez-vous" technique [4-6, 10-12]. Ciesielczyk and Murawa observed that 14 days following percutaneous drainage the level of bilirubin did not exceed $170 \mu \mathrm{mol} / \mathrm{l}$. After 30 days jaundice remitted in $52.6 \%$, and in the next $23.7 \%$ the level of bilirubin did not exceed $85 \mu \mathrm{mol} / \mathrm{l}$ [8]. In our patients we also observed in the follow-up tests $50 \%$ decrease of the bilirubin level in comparison to the initial values. After drainage the values of alkaline phosphatase, urea and hypokalaemia became normalized [8]. Sewnath et al. observed that after 4-6 weeks hepatocyte function also normalized [10]. The most frequent post-drainage complications pa- 
tients suffered were weakness, pain, inflammatorily infiltrate of skin surrounding the drain, and biliary leak at the drain [8]. Some authors have drawn attention to the possibility of cholangitis, sub-peritoneal abscess and gastroparesis [8, 12]. In our experience a drain falling out, which occurred in 3 cases (2.4\%), and biliary leak, also in 3 cases $(2.4 \%)$, were the most frequent complications. Drain obstruction took place in 1 case $(0.8 \%)$. Cholangitis turned out to be the most serious complication (1 patient). Urgent surgery was performed during which bypass anastomoses were performed (hepatic-jejunal and retrocolic gastro-jejunal). The patient, with serious concurrent diseases (ischaemic heart disease, arterial hypertension, chronic obstructive pulmonary disease, generalized arteriosclerosis), died on the $4^{\text {th }}$ postoperative day due to circular-respiratory insufficiency. It must be remembered that patients selected for mini-invasive management of jaundice decompression suffer different stages of generalized cancer and their survival times are weeks, less frequently months. Robson observed that $10 \%$ of patients died within 4 weeks and $28 \%$ within 8 weeks after the procedure [9]. Post-drainage complications affect a small percentage of patients, and in about $95 \%$ of cases the course is uncomplicated. The same results were observed in our patients $[4,9]$. Ciesielczyk et al. observed that $53.3 \%$ fully, and $33.4 \%$ partially accepted the method of treatment $[8,9]$.

\section{Conclusions}

Ultrasound-guided percutaneous drainage is generally a safe, well-tolerated method with only a few complications. It is an effective remedy for jaundice in patients with no other options of treatment. It may also be used, in some patients, as a preparatory phase before the surgery.

\section{References}

1. Covey AM, Brown KT. Palliative percutaneous drainage in malignant biliary obstruction. Part 1: indications and preprocedure evaluation. J Support Oncol 2006; 4: 269-73.

2. Covey AM, Brown KT. Palliative percutaneous drainage in malignant biliary obstruction. Part 2: Mechanisms and postprocedure management. J Support Oncol 2006; 4: 329-35.

3. Covey AM, Brown KT. Percutaneous transhepatic biliary drainage. Tech Vasc Interv Radiol 2008; 11: 14-20.

4. Neal CP, Thomasset SC, Bools D, et al. Combined percutaneousendoscopic stenting of malignant biliary obstruction: results from 106 consecutive procedures and identification of factors associated with adverse outcome. Surg Endosc 2010; 24: 423-31.
5. Piskorz Ł, Brocki M, Lesiak T, et al. Sposoby postępowania w różnych stopniach zaawansowania klinicznego raka trzustki. Pol Merkuriusz Lek 2007; 26: 395-8.

6. Sciume C, Geraci G, Pisello Fl, et al. "Randez-vous" technique for paliation of neoplastic jaundice: personal experience. Ann Ital Chir 2004; 75: 634-47.

7. Śmigielski J, Hołyński J, Kococik M, et al. Zabiegi paliatywne w raku pęcherzyka i/lub dróg żółciowych - doświadczenia 5 ośrodków. Pol Merkuriusz Lek 2009; 26: 416-9.

8. Ciesielczyk B, Murawa D. The results of palliative percutaneous drainage of biliary ducts. Rep Pract Oncol Radiother 2004; 9: 69-72.

9. Robson PC, Heffernan N, Gonen M, et al. Prospective study of outcomes after percutaneous biliary drainage for malignant biliary obstruction. Ann Surg Oncol 2010; 17: 2303-11.

10. Sewnath ME, Karsten TM, Prins MH, et al. A meta-analysis on the efficacy of preoperative biliary drainage for tumors causing obstructive jaundice. Ann Surg 2002; 236: 17-27.

11. Wang Q, Gurusamy KS, Lin H, et al. Preoperative biliary drainage for obstructive jaundice. Cochrane Database Syst Rev 2008; 16: 5444.

12. Yu-Dong Q, Jian-Ling B, Fang-Gui X, Yi-Tao D. Ding Effect of preoperative biliary drainage on malignant obstructive jaundice: a meta-analysis World J Gastroenterol 2011; 17: 391-6. 